\title{
Italian Digestive Endoscopists and Anesthesiologists Publish a Joint Document of Good Clinical Practice: It was Time!
}

\author{
Rita Conigliaro* \\ Head of Gastroenterology and Digestive Endoscopy Unit, University Hospital, Modena, Italy \\ *Corresponding author: Rita Conigliaro, Head of Gastroenterology and Digestive Endoscopy Unit, University Hospital, Modena, Italy; E-mail: conigliaro.rita@aou.mo.it
}

Received: August 21, 2021; Accepted: September 08, 2021; Published: September 15, 2021

\section{Introduction}

The problem of sedation in Digestive Endoscopy (DE) has been a source of debate and controversy both within the world of endoscopists and anesthetists and this not only in Italy but in Europe and around the world. Finally the Italian Society of Digestive Endoscopy (SIED) was able to initiate a debate with Italian Society of Anesthesia Analgesia Intensive Care Resuscitation (SIAARTI) and produce a common document of Good Clinical Practice applicable to all Services of national, public and accredited private Digestive Endoscopy Centers, in which the Anesthesiologists Specialist (AS) should be present. Therefore, in this article, a summary of the document is proposed which, starting from the European guidelines of the two disciplines [1-3], wanted to outline appropriate and sustainable clinicalorganizational paths, identifying the risks and the necessary skills, as well as the responsibilities, to guarantee the quality and safety of the diagnostic-therapeutic treatments offered in DE.

\section{Methodology}

A Panel of experts was set up, made up of 5 representatives from each of the two Scientific Societies who shared the methodology, defined a series of "clinical questions" to which answers in terms of operative proposals. Then the group proceeded to carry out the Literature Review updated, to elaborate a Survey at the Italian Endoscopy Centers to have "current information " on clinical practices in ED, to prepare a document and submit it to the respective Councils and scientific boards.

\section{The Document}

The document is divided into 7 points:

1. Definition of Sedation-Analgesia-Procedural, in ED.

2. Pre-procedural assessment and risk stratification of patients who are candidates for SAP in ED, defining the precautions to be activated (starting with the withdrawal times of solids and liquids).

3. SAP settings and minimum monitoring standards.

4. Responsibility profiles for SAP in ED. Definition of the role of the doctor of ED.
5. Drugs for sedation and definition of an appropriate use of Propofol for SAP.

6. Post-procedural control of the patient undergoing SAP, and management of possible complications.

7. Definition of the training path and maintenance of the skills of the candidate personnel to perform the SAP in ED.

As part of the document, the authors have introduced and shared some updated and appropriate standard concepts or approaches:

A first concept intoduced is included in the definition of Procedural Sedation-Analgesia (PSA) which defines a condition obtained with a hypnotic and/or analgesic to make an effective diagnostic or therapeutic endoscopic procedure possible, ensuring that the patient is closely monitored to prevent potential adverse effects! The "PSA" definitively replaces the ambiguous concept and term of "conscious" or "alert" sedation as sedation always determines a reduction in the level of consciousness and from being conscious it can become deep even without the use of hypnotics. Another important concept is that the figure of the "non-anesthesiologist operator who becomes" Anesthesia provider", or sedo-anesthesia administrator, is also contemplated in the anesthesiological literature [4].

Is absolutely mandatory for the endoscopist who wants to sedate the patient that first of all defines the risk of the patient (ASA score) [5]. Based on this assessment, the endoscopist must decide who to sedate independently and who to submit to anesthesiologist assistance and clearly summarizes the criteria for candidacy for Non-anesthesiologist sedation (NAS).

Are reported and shared the minimum standards that are necessary to perform the SAP in security and also specifies which and how many human resources are required for the correct management of the SAP.

Furthermore, for the first time in the Italian context, the profiles of responsibility in sedation are declared and shared: it is the endoscopist who decides the type of drug/s and the dosage, but administration and monitoring are the responsibility of the nurse in a team that has obviously been trained for the monitoring and management of sedation $[1,6,7]$. 
With regard to sedation drugs in particular, the paragraph of the document addresses the problem of the use of Propofol in NAS. This problem which remains very controversial in the world but in particular in Italy where the Italian Drugs Agency (AIFA) has also recently expressed itself restrictively, reiterating that the use of Propofol remains the prerogative of anesthesiologists. Despite this, the panel based on the new knowledge/information and clinical evidence emerging from the current scientific literature [3,7-13] which demonstrates the safety of the drug if used with adequate training states that it is necessary to take into account the effective skills of the endoscopist teams, that if they are prepared for the administration of Propofol, in agreement with the AR of their own hospital they can choose to administer Propofol in the NAS. Particularly valuable then is the part of the document on the management of the possible complications of sedation which are all listed explaining the cause, prevention and possible treatment.

The training and maintenance of the skills of the candidate personnel to perform the SAP in ED is described in the last paragraph. but in reality is the "core" of the Document and of the problem of self-managed sedation by non-anesthesiologist. In fact, if the staff is trained according to the SAP program performed in NAS as proposed by the main scientific societies in the sector $[6,14]$, it increases the safety of sedoanalgesia performed with all available drugs including Propofol.

\section{Conclusion}

The document reports the position of the Panel of experts on some points summarized in a final "Take Home Message":

- It is not possible to perform diagnostic and therapeutic endoscopic procedures without sedation

- Sedation today is Procedural Sedation-Analgesia (SAP) which defines a condition obtained with a hypnotic and/or an analgesic

- A pre-procedural assessment and risk stratification of the patients to be sedated in Settings appropriate to the recommendations of the Reference Guidelines is essential.

In accordance with the "Profiles of responsibility", the endoscopy teams can autonomously sedate ASA1 and 2 patients for procedures that are not too long or too complex after adequate training provided by the Departments/Units of RA.

\section{References}

1. Hinkelbein J, Lamperti M, Akeson J, et al. (2017) European Society of Anaesthesiology and European Board of Anaesthesiology guidelines for procedural sedation and analgesia in adults. Eur J Anaesthesiol 34: 1-19. [crossref]

2. Foley EM, Wolfe RE, Burstein J, et al. (2016) Utility of Procedural Sedation as a Marker for Quality Assurance in Emergency Medicine. J Emerg Med 50: 711-714. [crossref]

3. Dumonceau JM, Riphaus A, Schreiber F, et al. (2015) Non-anesthesiologist administration of propofol for gastrointestinal endoscopy: European Society of Gastrointestinal Endoscopy, European Society of Gastroenterology and Endoscopy Nurses andAssociates Guideline - Updated June 2015. Endoscopy 47: 1175-1189. [crossref]
4. World Health Organization-World Federation of Societies of Anaesthesiologists (WHO-WFSA) International Standards for a Safe Practice of Anesthesia (2018) Adrian W. Gelb, Wayne W. Morriss, Walter Johnson, Alan F. Merry, on behalf of the International Standards for a Safe Practice of AnesthesiaWorkgroup. Can J Anesth 126: 2047-2055. [crossref]

5. Mayhew D, Mendonca V, Murthy BVS (2019) A review of ASA physical status historical perspectives and modern developments. Anaesthesia 74: 373-379. [crossref]

6. Dumonceau JM, A Riphaus, U Beilenhoff, et al. (2013) European Curriculum for Sedation Training in Gastrointestinal Endoscopy: Position Statement of the European Society of Gastrointestinal Endoscopy (ESGE) and European Society of Gastroenterology and Endoscopy Nurses and Associates (ESGENA ) Endoscopy 45: 496-504. [crossref]

7. Burtea ED, Dimitriu A, Maloş AE et al. (2018) Periprocedural role of Nurses during Interventional Endoscopic procedures under deep sedation. Curr Health Sci J 44: 1418. [crossref]

8. Vargo JJ, Zuccaro G Jr, Dumot JA, et al. (2002) Gastroenterologist -administered propofol versus meperidine and midazolam for advanced upper endoscopy : a prospective, randomized trial . Gastroenterology 123 : 373-375. [crossref]

9. Conigliaro R, Fanti L, Manno M, Brosolo P (2017) Italian Society of Digestive Endoscopy (SIED). position paper on the non-anaesthesiologist administration of propofol for gastrointestinal endoscopy. Dig Liver Dis. 49: 1185-1190. [crossref]

10. Rex DK, Deenadayalu VP, Eid E, et al. (2009) Endoscopist-directed administration of Propofol: a worldwide safety experience. Gastroenterology 137: 1229-1237. [crossref]

11. Byrne MF, Chiba N, Singh H, et al. (2008) Propofol use for sedation during endoscopy in adults: a

12. Canadian Association of Gastroenterology position statement. Can J Gastroenterol 22: 457-459. [crossref]

13. Vargo JJ, Cohen LB, Rex DK, Kwo PY (2009) American Association for the Study of Liver Diseases; American College of Gastroenterology; American Gastroenterological Association, American Society for Gastrointestinal Endoscopy Position statement: nonanesthesiologist administration of Propofol for GI endoscopy. Gastroenterology 137: 2161-2167.

14. Daza JF, Tan CM, Fielding RJ, et al. (2018) Propofol administration by endoscopists versus anesthesiologists in gastrointestinal endoscopy: a systematic review and metaanalysis of patient safety outcomes. Can J Surg 61: 226-236. [crossref]

15. Cabadas Avión R, Baluja A, OjeaCendón M, et al. (2019) Effectiveness and safety of gastrointestinal endoscopy during specific sedation training program for non anesthesiologists. Rev Esp Enferm Dig 111: 199-208. [crossref]

\section{Citation:}

Conigliaro R (2021) Italian Digestive Endoscopists and Anesthesiologists Publish a Joint Document of Good Clinical Practice: It was Time! Internal Med Res Open J Volume 6(4): 1-2. 